\title{
Redox Homeostasis and Prospects for Therapeutic Targeting in Neurodegenerative Disorders
}

\author{
Musbau Adewumi Akanji $\mathbb{D}^{1}{ }^{1}$ Damilare Emmanuel Rotimi, ${ }^{2,3}$ Tobiloba Christiana Elebiyo, ${ }^{3}$ \\ Oluwakemi Josephine Awakan $\mathbb{D}^{2,3}$ and Oluyomi Stephen Adeyemi ${ }^{2,3}$ \\ ${ }^{1}$ Department of Biochemistry, University of Ilorin, Ilorin, Nigeria \\ ${ }^{2}$ Landmark University SDG 3 (Good Health and Well-being Research Group), PMB 1001, Omu-Aran 251101, Nigeria \\ ${ }^{3}$ Department of Biochemistry, Medicinal Biochemistry, Nanomedicine \& Toxicology Laboratory, Landmark University, KM 4 \\ Ipetu Road, Omu-Aran 251101, Kwara State, Nigeria
}

Correspondence should be addressed to Musbau Adewumi Akanji; akanjima@yahoo.com,

Oluwakemi Josephine Awakan; amira.oluwakemi@lmu.edu.ng, and Oluyomi Stephen Adeyemi; yomibowa@yahoo.com

Received 24 March 2021; Revised 27 May 2021; Accepted 20 July 2021; Published 3 August 2021

Academic Editor: Luciana Hannibal

Copyright (c) 2021 Musbau Adewumi Akanji et al. This is an open access article distributed under the Creative Commons Attribution License, which permits unrestricted use, distribution, and reproduction in any medium, provided the original work is properly cited.

\begin{abstract}
Reactive species, such as those of oxygen, nitrogen, and sulfur, are considered part of normal cellular metabolism and play significant roles that can impact several signaling processes in ways that lead to either cellular sustenance, protection, or damage. Cellular redox processes involve a balance in the production of reactive species (RS) and their removal because redox imbalance may facilitate oxidative damage. Physiologically, redox homeostasis is essential for the maintenance of many cellular processes. RS may serve as signaling molecules or cause oxidative cellular damage depending on the delicate equilibrium between RS production and their efficient removal through the use of enzymatic or nonenzymatic cellular mechanisms. Moreover, accumulating evidence suggests that redox imbalance plays a significant role in the progression of several neurodegenerative diseases. For example, studies have shown that redox imbalance in the brain mediates neurodegeneration and alters normal cytoprotective responses to stress. Therefore, this review describes redox homeostasis in neurodegenerative diseases with a focus on Alzheimer's and Parkinson's disease. A clearer understanding of the redox-regulated processes in neurodegenerative disorders may afford opportunities for newer therapeutic strategies.
\end{abstract}

\section{Introduction}

Neurodegeneration, which is characterized by gradual neuronal and synaptic degradation, glial focal proliferation, neuroinflammation, vascular abnormalities in specific brain regions, and modifications of proteins such as $\alpha$-synuclein, amyloid- $\beta$, and tau proteins [1-3], contributes significantly to the global health burden. The major groups of neurodegenerative diseases include Alzheimer's disease (AD), Parkinson's disease (PD), spinal muscular atrophy (SMA), prion diseases, spinocerebellar ataxia (SCA), motor neuron disease (MND), and Huntington's disease (HD). Different neurodegenerative diseases have a variety of pathophysiol- ogies, which include cognitive and memory impairments or the inability to move, speak, or breathe [4].

In the brain, a concomitant low activity of antioxidant defense mechanisms and the presence of highly redoxactive metals (copper and iron) allow for greater sensitivity to reactive oxygen species (ROS) than other organs [5]. Although oxygen is necessary for life, an imbalance between the number of ROS produced and the antioxidant system causes neural disorders. Although there is no unified etiology for neurodegenerative diseases, strong evidence has implicated oxidative stress in the pathogenesis of all forms of neurodegeneration [6,7]. Overproduction of reactive oxygen species in neuronal cells induces oxidative stress, which 
destroys neural mitochondrial defense mechanisms, causes mitochondrial DNA mutations, affects $\mathrm{Ca}^{2+}$ homeostasis, alters membrane permeability, and damages the mitochondrial respiratory chain. These modifications are thought to play a role in the progression of neurodegenerative disorders by mediating or amplifying neuronal dysfunction and causing neurodegeneration [5].

A series of events, such as oxidative stress, protein modification, and mtDNA damage, eventually results in impaired neuronal proteins, further resulting in neuroinflammation and neurological disorders, which manifest as cognitive function loss [8]. However, numerous antioxidant therapeutic targets have been identified that can protect neurons against oxidative stress by preventing free radical formation and modulating normal metal homeostasis [7]. Antioxidants are now being developed to treat neuronal inflammation and scavenge free radicals. The disruption of the redox potential in neurons often results in the oxidative modification of proteins, leading to aberrant peptide oligomerization and eventually neuronal death. Research efforts have focused on discovering agents that can protect against oxidative damage to neurons [9]. In this paper, we reviewed scientific reports on the pathogenesis and prospects for therapeutically targeting oxidative stress in neurodegenerative diseases, especially Alzheimer's and Parkinson's disease.

\section{Reactive Oxygen Species and Oxidative Stress}

Oxidative stress arises as a result of an imbalance in the oxidant/antioxidant ratio and can create a hazardous state that contributes to cellular damage due to a disequilibrium in the number of ROS molecules generated and the level of the antioxidant enzyme system that detoxifies the reactive intermediates in the biological system [10]. The majority of free radicals (hydrogen peroxide, superoxide anion radical, and hydroxyl radical) are produced by molecular oxygen activation (Figure 1$)$. Superoxide anion $\left(\mathrm{O}_{2}{ }^{--}\right)$is highly reactive and generated in the electron transport chain (ETC) through mitochondrial complexes I and III. $\mathrm{O}_{2}{ }^{--}$can be reduced to hydrogen peroxide $\left(\mathrm{H}_{2} \mathrm{O}_{2}\right)$ as it crosses the inner mitochondrial membrane [11]. Peroxisomes can also generate $\mathrm{H}_{2} \mathrm{O}_{2}$ in addition to what is produced by the mitochondria. However, catalase is present in the peroxisomes and is responsible for converting $\mathrm{H}_{2} \mathrm{O}_{2}$ to water, thereby preventing its buildup. However, if there is damage to the peroxisomes or the enzyme is downregulated, the release of $\mathrm{H}_{2} \mathrm{O}_{2}$ into the cytosol increases oxidative stress [12]. Direct pathways involving Fenton and Haber-Weiss reactions that occur between redox-active metals and oxygen species or indirect interactions involving enzyme activation (NADPH oxidase or nitric oxide synthase) are examples of pathways that generate $\operatorname{ROS}[13,14]$. The Fenton reaction in the presence of ferrous iron $\left(\mathrm{Fe}^{2+}\right)$ converts $\mathrm{H}_{2} \mathrm{O}_{2}$ into the most harmful ROS, the hydroxyl radical ( $\mathrm{OH}$ ) (Figure 1) [13].

ROS can also interact with nitric oxide to generate reactive nitrogen species resulting in nitrosative stress. NO is produced by one of the three synthase isoforms, inducible NO synthase (iNOS), endothelial NO synthase (eNOS), and neuronal NO synthase (nNOS), and is found in cells and in the extracellular space surrounding dopaminergic neurons. nNOS is expressed mainly in neurons, eNOS is expressed in the vascular endothelium, and iNOS is expressed in glial cells. These NOSs have been implicated in pathological conditions. Damaged mitochondria and activated microglia produce large amounts of iNOS and serve as the main sources of ROS in the inflammatory process, which is a hallmark of neurodegenerative diseases [15-18]. For instance, the production of NO by iNOS or nNOS in the extracellular space surrounding dopaminergic neurons and its subsequent reaction could involve interaction with superoxide to produce large quantities of peroxynitrite $\left(\mathrm{ONOO}^{-}\right)$(Figure 1) [19]. Compared to $\mathrm{NO}$, peroxynitrite is a more potent oxidizing agent and is an oxidatively more active molecule which can induce lipid peroxidation and DNA fragmentation [20]. The generated $\mathrm{ONOO}^{\circ}$ and $\mathrm{NO}$ can also modify proteins via nitration [21]. NO can also react with thiolate ions to form S-nitrosothiols, which may form adducts with protein or lipids. Another cellular mechanism implicated in neurodegenerative conditions that involve the production of ROS occurs in the endoplasmic reticulum (ER). $\mathrm{Ca}^{2+}$ release from the ER leads to the promotion of ROS generation when the $\mathrm{Ca}^{2+}$ enters the mitochondria and can also trigger mitochondrial-mediated apoptosis. Additionally, abnormal protein degradation and ER stress are considered to contribute to PD pathogenesis [22].

\section{Neuronal ROS Generation}

Cellular ROS can be generated via exogenous and endogenous sources. Exogenous sources include metabolism of xenobiotics and exposure to ultraviolet and ionizing radiation, whereas endogenous generation is mediated by enzymes such as NADH, coenzyme Q oxidoreductase (complex 1), ubiquinol cytochrome $\mathrm{C}$ reductase (complex III), NADPH oxidase (NOX), lipoxygenase (LOX), cyclooxygenase (COX), xanthine oxidase (XO), the cytochrome p450 family of enzymes, and flavin oxidase. The majority of these enzymes are localized in the mitochondria, and as such, the mitochondria are the primary source for the endogenous generation of ROS [23].

Neurons are energy-demanding cells; as such, they are extremely sensitive to changes in mitochondrial function. They depend on the mitochondria for ATP generation and calcium regulation, processes required for synaptic transmission, vesicle recycling, neuronal electrical activity, and axonal transport [6]. Thus, deficiencies in mitochondrial function ultimately result in the degradation of neurons. Neurodegeneration is an age-related disease; it is associated with mitochondria, DNA damage, mutations, and deletions, which increase in an age-dependent manner. Based on evidence, the levels of mutated or deleted mtDNA are the highest in the substantia nigra (SN) and cerebral cortex (CC) of adult humans in normal aging, and these damages are often $1 \%$ higher in patients with neurodegenerative diseases [24]. The neurons in the brain regions of subjects with neurodegenerative diseases often show alterations in the ETC, intracellular ROS levels, and calcium homeostasis. The processes of mitochondrial fusion and fission are deregulated in most 


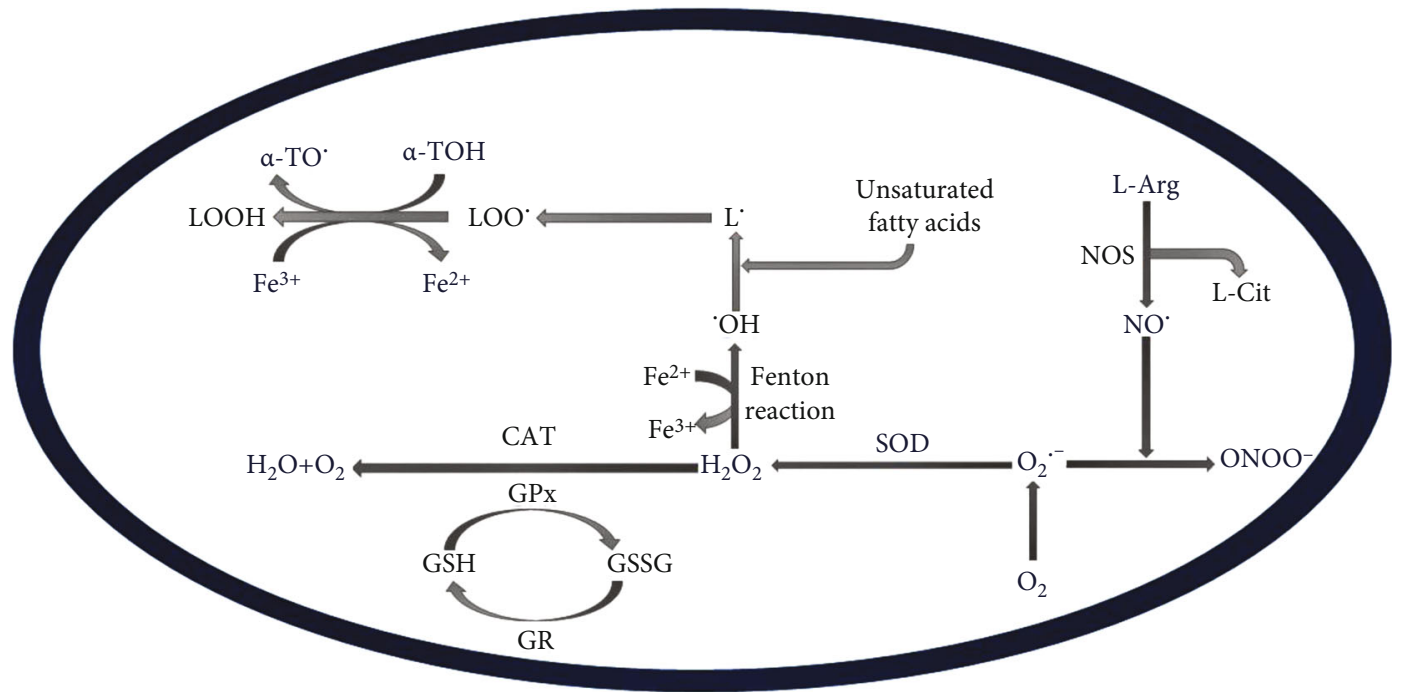

Figure 1: Generation of reactive oxygen species and reactive nitrogen species. $\mathrm{H}_{2} \mathrm{O}$ : water; $\mathrm{O}_{2}$ : oxygen; $\mathrm{O}_{2}{ }^{--}$: superoxide anion; $\mathrm{H}_{2} \mathrm{O}_{2}$ : hydrogen peroxide; CAT: catalase; SOD: superoxide dismutase; $\mathrm{ONOO}^{-}$: peroxynitrite; GSH: reduced glutathione; GSSG: glutathione disulfide; $\mathrm{Fe}^{2+}$ : ferrous iron; $\mathrm{OH}$ : hydroxyl radical; NOS: nitric oxide synthase; L-Arg: L-arginine; L-Cit: L-citrulline; NO: nitric oxide radical; LOOH: lipid hydroperoxides; LOO: lipid peroxy radical; $\alpha$-TOH: $\alpha$-tocopherol; $\alpha$-TO: $\alpha$-tocopheroxyl radical.

neurodegenerative diseases, leading to impaired neuronal plasticity and development [6].

Mitochondrial dysfunction and the increased generation of ROS alter dopamine metabolism and calcium and iron homeostasis, resulting in the death of dopaminergic neurons in the substantia nigra pars compacta $(\mathrm{SNpc})$. The eventual depletion of antioxidants such as glutathione (GSH) also leads to the generation and accumulation of lipid peroxides as ROS interacts with abundant polyunsaturated fatty acids (PUFA) in the brain [25-27]. Reports also show that aging is accompanied by an increased level of iron and copper in the brain tissue; such alterations in ion homeostasis could initiate excitotoxicity via the overactivation of neuronal receptors such as $\mathrm{N}$-methyl-D-aspartate (NMDA) receptors [28]. The aberrant activation of NMDA receptors produces high levels of NO, which could interact with superoxide and induce nitrosative stress [29].

\section{Sources of ROS Generation in Neurons}

4.1. Iron. Ions such as iron and calcium are involved in the generation of ROS. Postmortem evaluation of the brains of patients with ND (neuronal disease) indicates that alterations in the levels of certain ions are present in the specific brain regions of ND patients compared with non-ND [30]. Iron is an indispensable cofactor for the synthesis of catecholamine neurotransmitters, but neuronal iron overload is a characteristic feature of neurodegenerative diseases [31]. In dysfunctional neurons, iron is transported from the extracellular matrix around the neurons via mechanisms such as transport via transferrin lactoferrin and hemopexin receptors and divalent metal transporter 1 as well as by heme degradation by heme oxygenase 2 [31-33]. Since iron is abundant in dysfunctional neurons, free iron interacts with the reaction between superoxide and hydrogen peroxide with ferrous iron $\left(\mathrm{Fe}^{2+}\right)$ and ferric iron $\left(\mathrm{Fe}^{3+}\right)$ resulting in the formation of a highly reactive hydroxyl free radical. Neuronal iron overload in ND is often accompanied by depleted iron concentration in the extracellular matrix; this results in poor iron incorporation into protein structures, premature protein degradation, and loss of protein function [31, 34-36]. Lewy's SN bodies of PD patients are characterized by nitrosylated iron-regulated protein 2 (IRP), which promotes the possibility of oxidative stress and iron dysfunction [37].

The human brain is heavily endowed with PUFAs, such as docosahexaenoic acid and arachidonic acid, which are required to fortify the blood-brain barrier (BBB). This makes the cell membrane of brain tissues susceptible to lipid peroxidation and oxidative damage [38]. Interaction between iron and lipid hydroperoxides results in the production of alkoxyl radicals, which further react in the presence of free reactive iron with polyunsaturated fatty acids to generate more lipid peroxides. 4-Hydroxy-2-nonenal (HNE), which is a lipid peroxide associated with $\mathrm{PD}$ and $\mathrm{AD}$, forms stable adducts with amine or thiol groups in proteins and may, in turn, result in the aberrant activation of caspases, leading to neuronal death $[39,40]$. HNE reactivity with sulfhydryl groups also depletes the GSH level, making the brain tissue more susceptible to oxidative stress. High HNE levels have been detected in the cerebrospinal fluid of patients with PD and AD [41].

4.2. Zinc and ROS Generation. Experiment carried out on mouse cortical cultures showed mitochondrial ROS production induced by zinc, possibly via inhibition of the lipoamide dehydrogenase (LADH) component of alpha-ketoglutarate dehydrogenase complex (KGDHC) in the TCA cycle [42, 43]. $\mathrm{LADH}$ catalyses $\mathrm{NAD}^{+}$reduction to $\mathrm{NADH}$, but zinc inhibits this process and favours NADH oxidation in the mitochondrial matrix. This reaction produces superoxide, which is converted to $\mathrm{H}_{2} \mathrm{O}_{2}$. Complex III inhibition by zinc also generates ROS in rat brain mitochondria which is also similar to that reported in mitochondria isolated from rat 
hearts $[44,45]$. ROS generation via zinc may be a result of its inhibition of ETC components and TCA cycle. Some other sources of zinc-induced ROS generation include nicotinamide adenine dinucleotide phosphate (NAPDH) oxidase (NOX) upregulation. NOX converts NADPH and oxygen to NADP+, superoxide and a hydrogen ion $[46,47]$.

4.3. Aluminium and ROS Generation. Aluminium (Al) generates highly reactive oxy and hydroxy free radicals which result in mitochondrial damage. Al increases oxidative stress via mediated Fenton reactions which increase the concentration of iron and it can also lead to $\mathrm{H}_{2} \mathrm{O}_{2}$ accumulation [48]. $\mathrm{Al}$ also activates SOD and inhibits CAT. Increase in $\mathrm{H}_{2} \mathrm{O}_{2}$ pool increases redox-active iron present either by modulating the electron transport chain or from loosely bound Fe. Studies have shown that oxidative stress and $\mathrm{A} \beta$ are closely linked and $\mathrm{Al}$ increases the production of $\mathrm{A} \beta$, leading to aggregation [49]. Another study also revealed that $\mathrm{Al}$ initially enhances oxidative stress, redox-active iron, and $\mathrm{A} \beta$ immunoreactivity $[50,51]$. The Fenton reaction helps $\mathrm{Al}$ to cause a lot of havoc via increasing the redox active iron concentration in the brain. Thus, Al significantly plays a role in neurodegeneration through oxidative stress.

\section{Parkinson's Disease and Oxidative Stress}

Parkinson's disease (PD) is a major neurological disease common among the aged ( $>60$ years); it is characterized by a progressive loss of motor control [52]. PD has become the second most reported neurodegenerative disease with around 10 million people having the condition worldwide [53]. PD is more predominant among men than women and seems to be strongly attributable to exposure to environmental toxins, illness, and head trauma [54]. Some of the clinical features of PD are impaired balance, tremor, rigidity, and bradykinesia, which progress to cognitive, sensory, psychiatric, and autonomic impairments [55]. Other manifestations of PD include memory loss, depression, anxiety, insecurity, stress, constipation, diminished sense of smell, difficulty in swallowing and excessive salivation, skin problems, confusion, erectile dysfunction, increased sweating, and a monotone voice [56].

The main risk factor for Parkinson's disease is age, with the disease's occurrence increasing exponentially after 60 years. Apart from the years it takes for pathogenic proteins to misfold to the point where they cause neuronal damage, age-related mitochondrial dysfunction and high generation of ROS are vital factors in neurodegenerative disorders [57]. Elevated deletions in mtDNA are reported in SN pigmented neurons in aged and PD-affected brains [58]. mtDNA damage results in the expression of mutant forms of ETC subunits and mitochondrial tRNAs, both of which contribute to aberrant ROS production, leading to a vicious cycle of mtDNA damage and other mitochondrial dysfunction, which also increase the development of ROS (Figure 2).

Sustained exposure to pesticides and insecticides has been identified as a risk factor for PD. According to Marras et al. [54], higher levels of pesticides and organochlorine insecticides and their metabolites can be detected in the serum and SN of PD patients than of non-PD subjects. Silver et al. [59] also suggested that the utilization of well-water contaminated with pesticides could increase the PD risk. Paraquat and rotenone, active ingredients in herbicides and pesticides, have been linked to $\mathrm{PD}$-associated oxidative stress upon entry into a biological system; they are metabolized to generate reactive species, which could damage mtDNA and inhibit enzymes involved in the ETC [60-62].

The pathogenesis of $\mathrm{PD}$ has shown that the disease involves the gradual and selective degradation of neurons in the $\mathrm{SN}$, an area responsible for movement. The SN contains numerous neurons that release dopamine and then communicate with both the basal ganglia and the frontal lobe responsible for the movement [63]. The oxidation of dopamine to produce dopamine quinones results in a generation of a highly reactive aminochrome that generates superoxides and depletes NADPH pools [64]. Aminochrome in turn forms an adduct with $\alpha$-synuclein, and this stimulates disease progression. Postmortem brain analysis in the SN of PD patients has revealed a significant increase in dopamine cysteinyl adducts $[65,66]$. Dopamine cysteinyl adducts become a precursor for the synthesis of neuromelanin, a molecule responsible for inflammation and degeneration in catecholaminergic neurons (Figure 2) [65, 67].

Postmortem examination of the SN brain regions of $\mathrm{PD}$ patients indicates a significant reduction in reduced glutathione (GSH) levels relative to glutathione disulfide (GSSG) level ratio (GSH/GSSG ratio) compared to non-PD patients [68]. The decreased GSH levels could be indicative of glutathione reductase inhibition in the SN of PD subjects as studies have shown that progressive nigral dopaminergic neurodegeneration leads to a downregulation of GSH production $[25,69]$.

Interestingly, mitochondrial anomalies have also long been considered as a major factor underlying $\mathrm{PD}$ pathogenesis, and studies have revealed the huge part played by mitochondrial dynamics and quality control in PD. In brief, implications of the involvement of mitochondrial dysfunction in PD stem from findings that (1) substantia nigra neurons from PD patients exhibit accumulations of mtDNA deletions; (2) significant deficits occur in the activity of mitochondrial respiratory chain complex I; and mutants of PINK1 , DJ-1, and Parkin, which are involved in mitochondrial functioning $[70,71]$, are found in PD.

\section{Alzheimer's Disease and Oxidative Stress}

Alzheimer's disease (AD) is an irreversible neurodegenerative disease, characterized by neuronal degradation in brain regions that control cognitive, memory, and emotional functions [72]. AD is age-related, progressive in nature, and can only be managed but not cured. The global prevalence of $\mathrm{AD}$ is estimated to rise from 26 million cases to 100 million cases by $2050[73,74]$.

The hallmarks of Alzheimer's disease are the formation of neurofibrillary tangles and senile plaques, neuronal and synaptic loss, severe neuroinflammation, and a global decrease in brain volume $[72,75]$. Although the complex nature of $\mathrm{AD}$ makes it difficult to accurately diagnose in living patients, advances in biomedical engineering have 


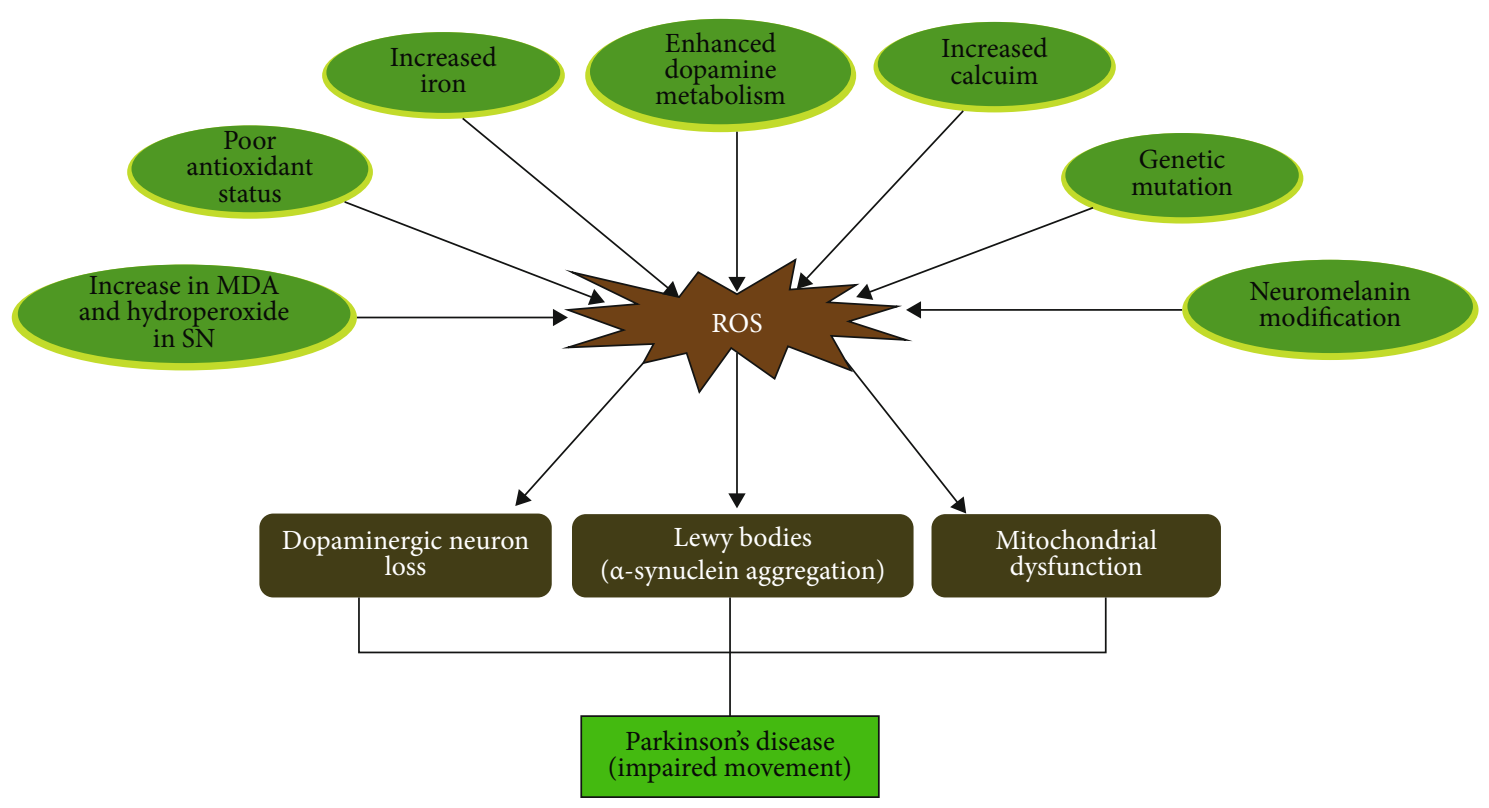

FIgure 2: The role of oxidative stress in the pathology of Parkinson's disease.

provided a wide array of tools that can diagnose AD in living patients with at least $95 \%$ accuracy. These tools include clinical tests to rule out other disease states, such as deficiencies in certain vitamins, infections, cancers, depression; neuropsychological tests for the evaluation of cognitive function; the use of cerebrospinal fluid protein analysis to differentiate $\mathrm{AD}$ from other dementias, especially, Creutzfeldt-Jakob disease, Lewy body dementia, or frontotemporal dementia; magnetic resonance imaging to check for shrinkage of brain regions responsible for learning and memory; and the detection of abnormal protein deposits using positron emission tomography scans $[74,76]$.

The etiology of AD is sporadic, and there is no single generally accepted cause of AD. However, about 5\% of known cases are caused by a germline mutation in presenilin 1 or 2 (PSEN 1 or 2) and/or amyloid precursor protein (APP) [77]. After translation of the APP gene to about 11 different isoforms, the protein undergoes amyloidogenic or nonamyloidogenic posttranslational modifications into various proteins, one of which is the amyloid- $\beta(\mathrm{A} \beta)$ protein, a prominent culprit in the pathology and progression of $\mathrm{AD}$ [78]. Mutations in the APP gene produce misfolded A $\beta$ peptides/proteins. The resultant formation of senile plaques fosters neurofibrillary tangle synthesis via tau protein hyperphosphorylation, a second protein culprit in the pathogenesis of $\mathrm{AD}[79,80]$. The neurofibrillary tangles and senile plaque accumulation may occur decades before cognitive and memory deficits are observed in AD patients [81].

Mitochondrial morphology has become a major factor in $\mathrm{AD}$ pathogenesis. For instance, compared with age-matched controls, AD neurons contain a large number of mitochondria with broken cristae. Also, the size and number of the neuronal mitochondria, especially those of the CA1/CA3 regions of the hippocampus, dentate gyrus, and the entorhinal cortex, differ from those in normal participants [82, 83]. Furthermore, fibroblasts from $\mathrm{AD}$ patients demonstrate abnormal mitochondrial dynamics [82]. The overall expression levels of the fission/fusion proteins DLP-1, OPA-1, Mfn1 and 2, and Fis1 are altered in AD (Figure 3).

Extensive research on the pathology of AD indicates that $\mathrm{A} \beta$ hastens the synthesis of neurofibrillary tangles via the activation of specific kinases involved in tau protein phosphorylation $[84,85]$. Normal tau proteins are "natively unfolded" and have an extremely low tendency towards misfolding, aggregation, and accumulation (Figure 3). They are involved in microtubule assembly and stability. Microtubules are the structural and functional backbone of neurons and are involved in intracellular trafficking and transport and in the maintenance of cell polarity and microtubules [86, 87], so normal tau proteins are also indirectly involved in these roles. Upon hyperphosphorylation, tau proteins lose their charge and conformation, which causes them to selfaggregate and oligomerize [88, 89]. These aggregates are eventually converted to intracellular neurofibrillary tangles, which result in microtubule disassembly, leading to the cessation of intracellular transduction and to neuroinflammation and neuronal degradation [90, 91].

$\mathrm{AD}$ progresses in three stages. First, there is the gradual buildup of extracellular senile plaques and intracellular neurofibrillary tangles, followed by mild cognitive impairment (MCI), which is linked with the buildup of plaques and tangles, and ending with early AD [72]. Several in vitro studies suggest that mitochondrial dysfunctions resulting from the production of reactive oxygen species (ROS) and reactive nitrogen species (RNS) [72, 92-94] play a detrimental role in the progression of AD. Oxidative-associated modifications in membrane-associated macromolecules and nucleic acids have been noted in the brains of AD subjects [95]. According to Haluska et al. [96], increased levels of lipid peroxides and aldehyde-4-hydroxynonenal (HNE) were detected in the brain during the early stages of $\mathrm{AD}$ models. Oxidation of nuclear and mitochondrial DNA/RNA molecules, especially 


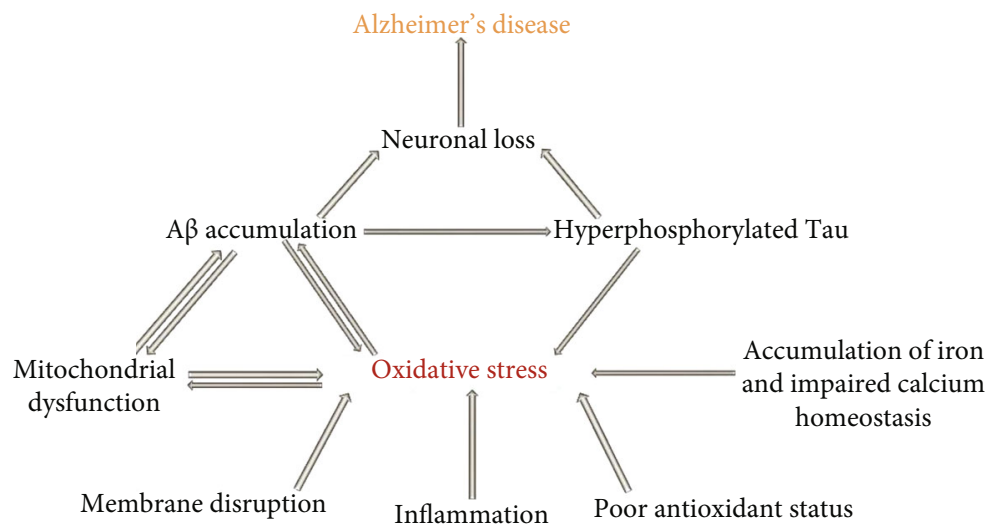

Figure 3: The role of oxidative stress in Alzheimer's disease.

of guanosine bases to 8-hydroxyguanosine, in brain regions that coordinate cognitive and emotional functions has also been documented [95].

Redox proteomics is essential for identifying specific proteins that are differentially oxidized in specific brain regions of AD patients. Specifically, several analyses have shown that the levels of protein nitration, protein carbonyls, and 4hydroxynonenal-modified proteins increase significantly in the brains of MCI AD patients $[97,98]$. The identified oxidatively modified proteins involved in regulating energy metabolism, cellular communication, and tau hyperphosphorylation include phosphoglycerate, enolase 1, pyruvate kinase, lactate dehydrogenase, peroxiredoxin, creatine kinase $\mathrm{B}$, glucose-regulated protein precursor, glutamine synthetase, actin, $\alpha$-tubulin, neuropolypeptide, and prolyl isomerase [72].

$\mathrm{AD}$-associated oxidative stress is mediated by $\mathrm{A} \beta$, which fosters disease progression. For instance, Giraldo et al. [99] stated that $\mathrm{A} \beta$-mediated oxidative stress triggers the oxidation of both NADPH oxidase and p38; the aberrant activation of $\mathrm{p} 38$, in turn, triggers the hyperphosphorylation of tau proteins. A $\beta$-mediated oxidative stress also plays an important role in the activation of calcineurin, sometimes known as a death molecule, which activates Bcl-2 deathassociated proteins and fosters cytochrome $c$ release from the mitochondria resulting in the apoptotic death of neurons [100]. A $\beta$ deposits contain elevated levels of copper, zinc, and iron ions, which could interact with $\mathrm{A} \beta$ to produce $\mathrm{ROS}$ via the Fenton reaction [101]. These ions could also bind to tyrosine and histidine residues of $\mathrm{A} \beta$, resulting in the oligomerization of $\mathrm{A} \beta$ proteins to form senile plaques [102, 103].

\section{Therapeutic Intervention in Parkinson and Alzheimer's Disease}

Over the last few years, intense study on multiple fronts has advanced the understanding of the genetics and mechanisms of neuronal pathogenesis and has contributed greatly to our understanding of neurodegenerative diseases, creating a basis for innovative technologies and therapeutic interventions against neurodegenerative diseases [4]. However, there are no available drugs for delaying the progression of $\mathrm{PD}$ or
AD although some drugs have been approved for the relief of $\mathrm{PD}$ and $\mathrm{AD}$ symptoms. Available therapeutic agents for PD often work by inhibiting striatal cholinergic effects or enhancing the activity of dopaminergic neurons [104]. Inhibitors of N-methyl-D-aspartic acid (NMDA), such as memantine and acetylcholinesterase (AChE), which include donepezil, rivastigmine, and galantamine, are also currently used to alleviate AD-related symptoms. Although these agents have succeeded in stimulating mild improvements in cognitive and memory functions, they do not reverse or delay PD and AD progression [101]. Since oxidative stress has been implicated in the pathology and progression of $\mathrm{AD}$, current research trends are shifting focus to the use of antioxidative agents in PD and AD treatment.

The molecules that have displayed great antioxidant activity when treating neurodegenerative diseases in in vitro and in vivo models are present in pure natural products or plant extracts. However, clinical outcomes in human patients have had limited success and are still inconclusive. This could be linked to the use of single compounds in most clinical trials. In contrast, preclinical studies have used plant extracts that contain several secondary metabolites. The synergistic effects of several active ingredients may provide better antioxidant/disease-modifying activity (Figures 4 and 5) [105-108].

\section{Targeting Oxidative Stress in Parkinson's Disease}

Antioxidants protected against PD pathogenesis in several in vitro and in vivo studies. However, the defense was only partial, leaving an open window for identifying more appropriate antioxidants for use as PD therapeutics [9]. Endogenous antioxidants, such as coenzyme Q10 (CoQ10), protect cells from oxidative stress (Figure 4). Coenzyme Q10, which is expressed in the mitochondria, acts as a free radical scavenger and electron carrier and accepts electrons released by complexes I and II. Coenzyme Q10 functions as a cofactor and may reduce free radical formation by activating the mitochondrial uncoupling protein. CoQ10 and creatine have shown great promise and are undergoing clinical trials for Parkinson's disease [109, 110].CoQ10 is involved in $\alpha$ - 


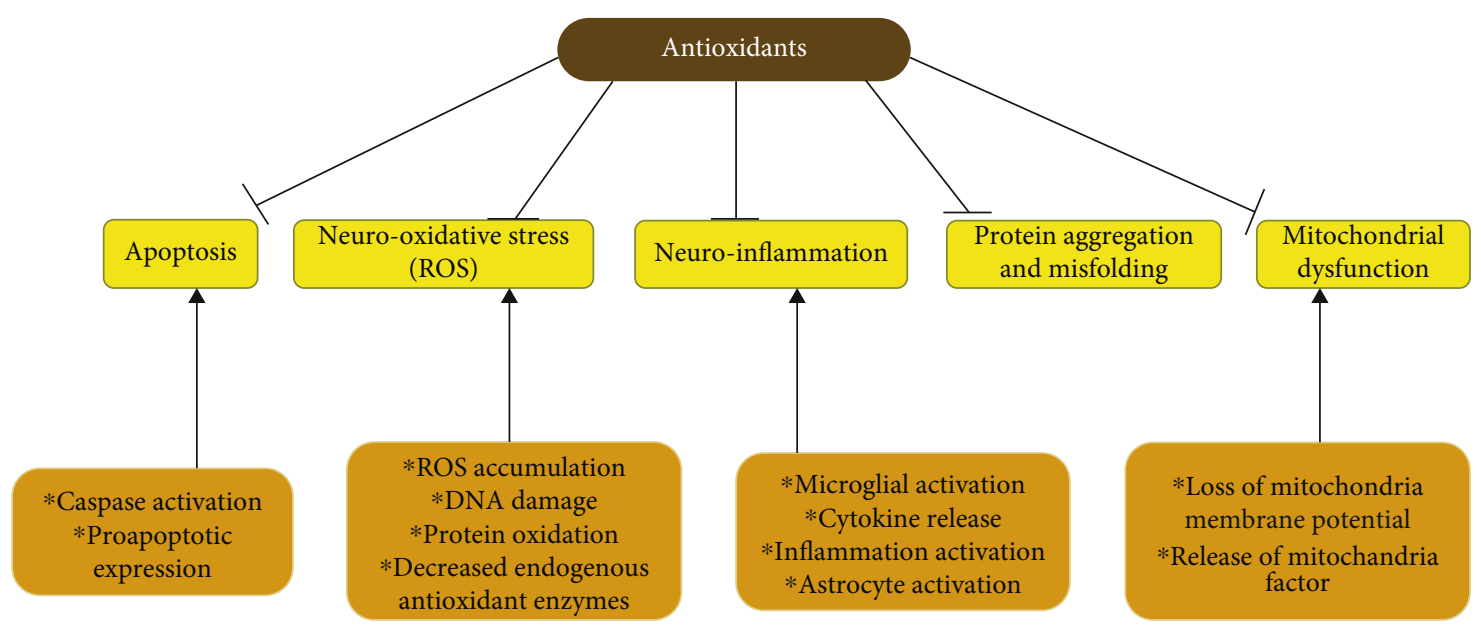

Figure 4: Antioxidant intervention at the cellular and molecular levels in neurodegeneration.

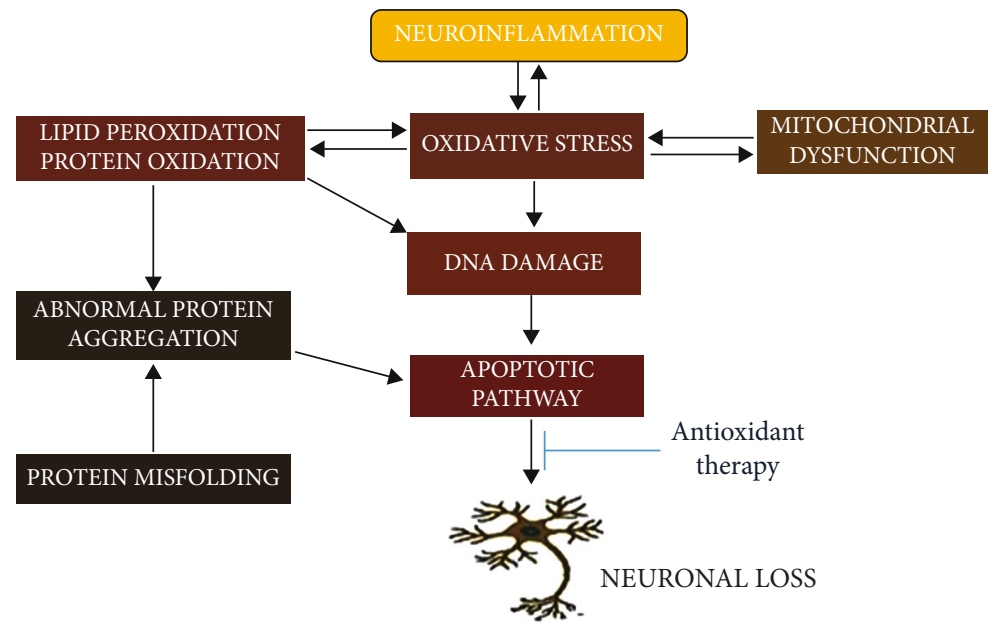

FIgURE 5: Schematic diagram on the effects of antioxidant on neuronal damage.

tocopheroxyl radical reduction and the regeneration of $\alpha$ tocopherol, making it a powerful free radical scavenger. CoQ10, which reduces the generation of free radicals and regulates the production of ATP, is also a required cofactor for mitochondrial uncoupling proteins [111].

Curiously, CoQ10 levels are reduced in platelets of PD patients, and this may correspond to mitochondrial complex I activity deficiency [112]. CoQ10 has also been shown to prevent death from oxidative stress, apoptosis, and cell death by inhibiting the mitochondrial permeability transfer pore (MPTP), which causes cell death by increasing mitochondrial calcium retention. Because of the decreased level of CoQ10 in PD patients, ATP synthesis is altered and mitochondrial membrane disruption occurs. Significantly improved mitochondrial dysfunction, depletion of dopamine, and axonal degeneration of dopamine neurons following oral CoQ10 were also found in experimental models of PD and in PD patients [113]. CoQ10's underlying protective mechanism is still not clearly defined. CoQ10 may reduce apoptosis by decreasing the $\mathrm{Bl}-2$ antiapoptotic factor level, inhibits cytochrome $c$ release to maintain the integrity of the membrane, and stops caspase 3 and caspase 9 activation to protect cells against apoptosis [96]. Other naturally occurring cellular molecules, such as creatine, have shown antioxidative properties [114].

The use of creatine in PD treatment is not well established, so further investigation is required. Exogenous polyphenolic compounds such as curcumin, resveratrol, quercetin, puerarin, luteolin, genistein, epigallocatechin gallate, baicalein, and citrus flavonoids (naringenin and hesperidin) can cross the blood-brain barrier and may be neuroprotective during the progression of Parkinson's disease. Extensive research has shown that diets supplemented with polyphenols are beneficial to health. Polyphenols provide neuroprotection against a variety of neuropathological and neurodegenerative conditions $[115,116]$.

Studies of the pathways of the Nrf2/antioxidant response element (ARE) indicate that it protects neurons from the PD insult of oxidative stress (OS). Two novel drug categories involving this signaling pathway have been developed. These are pathologically activated therapeutics and proelectrophilic drugs, both of which activate the Nrf2/ARE pathway through 
TABLE 1: Natural compounds with therapeutic action against neurodegeneration disorders.

\begin{tabular}{|c|c|c|c|}
\hline Compounds & $\begin{array}{c}\text { Therapeutic } \\
\text { target }\end{array}$ & Mechanism of action & Reference \\
\hline Coenzyme q10 & $\mathrm{PD}$ & $\begin{array}{l}\alpha \text {-Tocopheroxyl radical reduction and regeneration of } \alpha \text { - } \\
\quad \text { tocopherol } \\
\text { Suppression of nigrostriatal dopaminergic cell death }\end{array}$ & {$[9,110,113]$} \\
\hline Luteolin & $\mathrm{PD}$ & Increases dopamine uptake & [139] \\
\hline Resveratrol & $\mathrm{PD}, \mathrm{AD}$ & Nrf2 activation & $\begin{array}{c}{[115,116,123,} \\
135]\end{array}$ \\
\hline Curcumin & $\mathrm{PD}$ & Nrf2 activation & {$[123]$} \\
\hline Epigallocatechin gallate & $\mathrm{PD}$ & Nrf2 activation & {$[123]$} \\
\hline$\alpha$-Tocopherol & $\mathrm{AD}$ & Proteolytic degradation of $A \beta$ plaques & {$[130-133]$} \\
\hline Quercetin & $\mathrm{PD}$ & Scavenges hydroxyl radicals & {$[140]$} \\
\hline Selenium & $\mathrm{AD}$ & Proteolytic degradation of $A \beta$ plaques & {$[130-133]$} \\
\hline 8-Hydroxyquinoline derivative & $\mathrm{AD}$ & Inhibit $\mathrm{A} \beta$ fibril formation and aggregation & {$[82]$} \\
\hline $\begin{array}{l}\mathrm{N} \text {-(4-Phenoxybenzyl) aniline } \\
\text { derivative }\end{array}$ & $\mathrm{AD}$ & Inhibition of acetylcholinesterase & {$[137]$} \\
\hline
\end{tabular}

powerful cellular defense systems against OS [117]. In SHSY5Y cell models of PD, high Nrf2 protein levels and gene activation of the ARE pathway were induced by naringenin, a natural flavonoid compound [118]. Lou and colleagues demonstrated that 6-OHDA-induced oxidation in $\mathrm{SH}$ SY5Y cells was ameliorated by naringenin via Nrf2/ARE signaling [118]. Additionally, an antioxidant effect of a small catechol, 3,4-dihydroxybenzalacetone, is also involved in the AKT/Nrf2/glutathione pathway [119]. Wei et al. found that Wnt3a could reduce 6-OHDA-induced neurotoxicity through the activation of the Wnt/b-catenin pathway, implying that the mechanism underlying OS inhibition is related to mitochondrial functional maintenance [120].

Moreover, several antioxidants have been studied to determine if they can improve the damage caused by OS in Parkinson's disease. For example, behavioral studies indicated that sulforaphane reduced 6-OHDA-induced rotation and motor coordination deficits in mice [121]. Standardized extracts of Hypericum perforatum, gallic acid, and Sida cordifolia had potent antioxidant activities in a 6-OHDA rotenone-induced rat model of Parkinson's disease [122]. Several drugs, heavy metals, carotenoids, oxathiolene oxides, dimercaptans, dithiocarbamates, trivalent arsenicals, 1,2dithiole-3-thiones, isothiocyanates, and quinones, have been reported to interact with specific redox-sensitive cysteines in Keap1 to dissociate Nrf2 from Keap1. There is strong evidence that these Nrf2 inducers may help slow down PD progression [123]. Similar results have been reported for dietary polyphenols, such as resveratrol, curcumin, or certain catechols. In addition, dopamine agonist (DA) and its derivatives as well as levodopa may hold prospects for PD treatment. These compounds are not electrophilic, but become electrophilic by oxidative conversion, which leads to increased expression and activity of GSK-3 $\beta$ (glycogen synthase kinase-3 beta). Besides aging, the major risk factor for PD has been identified as being a steady increase in GSK-3 $\beta$ activity and a decline in Nrf2 transcriptional activity. GSK-3 $\beta$ inhibitors including antioxidative phytochemicals have been shown to protect against the death of oxidative neuronal cells induced by stress [124, 125]. Overall, phytochemicals appear to be a promising treatment option for current neurodegenerative diseases.

Finally, understanding the link between oxidative stress and impaired mitochondrial function could indicate that targeting oxidative stress by using antioxidants may also confer protection for mitochondria. Preclinical studies have shown that mitochondria-targeted antioxidants (such as CoQ10, vitamin E, MitoQ, or urate) improve mitochondrial activity, but creatine, MitoQ, and coenzyme Q10 did not demonstrate disease-modifying benefits in PD patients in clinical trials. Taking these results together indicates that oxidative stress is a downstream effect of mitochondrial dysfunction rather than a direct cause of PD-related neurodegeneration [126129].

\section{Targeting Oxidative Stress in Alzheimer's Disease}

Some experiments in transgenic mouse models and some human clinical trials demonstrated that $\alpha$-tocopherol- and selenium-supplemented diets promote the proteolytic degradation of $\mathrm{A} \beta$ plaques, ameliorate the aggregation of tau proteins, and improve cognitive function [130-133]. These findings were, however, contradicted by a 5 -year clinical trial that revealed that the supplemental use of $\alpha$-tocopherol and selenium only treated AD symptoms but did not prevent the progression of $\mathrm{AD}$ [134]. According to Yang et al. [135], the little or no improvement in cognitive function in response to antioxidant supplements during clinical trials could have resulted from ineffective delivery of the antioxidant to the mitochondria of neurons. With that in mind, some researchers now focus on the targeted delivery of antioxidants to the mitochondria of neurons. Gao et al. [136] reported that the biomimetic nanosystem designed for their study effectively crossed the blood-brain barrier and delivered curcumin to the mitochondria of neurons. Based on the findings reported by Yang et al. [135], the resveratrol- 
encapsulated neuronal mitochondria-targeted micelle designed for their study was able to facilitate the delivery of high levels of resveratrol into the brain mitochondria; this efficiently reduced oxidative stress, decreased $\mathrm{A} \beta$ plaque formation, and ameliorated tau hyperphosphorylation, neuroinflammation, and declined memory function in an aged AD mice model.

Another strategy that has been adopted for targeting oxidative stress in $\mathrm{AD}$ patients involves the use of $\mathrm{AChE}$ inhibitors with strong antioxidant potential and good blood-brain barrier-permeating abilities. According to Yang et al. [101], a series of newly synthesized 8-hydroxyquinoline derivatives with good brain barrier permeating ability, strong antioxidative activity, and significant metal-chelating ability was able to inhibit the generation of $\mathrm{A} \beta$ fibrils and aggregates in $\mathrm{AD}$ mouse models. Srivastava et al. [137] also reported that a new class of $\mathrm{N}$-(4-phenoxybenzyl) aniline derivatives designed for their study improved learning and memory functions in transgenic mice via mechanisms that involve the inhibition of acetylcholinesterase, the formation of $A \beta$ aggregates, and the reduction of oxidative stress.

Recently, the pharmacologically developed compound diethyl(3,4-dihydroxyphenethylamino) (quinolin-4-yl) methylphosphonate (DDQ) demonstrated positive effects on mRNA and protein levels related to mitochondrial dysfunction and synaptic dysregulation. DDQ also had an effect on mitochondrial dynamics related to $\mathrm{A} \beta$ interactions, fusion proteins (Mfn1 and 2), and fission proteins (Lis1 and DRP1) [138]. The table below shows a summary of natural antioxidative compounds that have been reported for therapeutic effects against $\mathrm{AD}$ and $\mathrm{PD}$ (Table 1).

\section{Future Directions}

The intervention of a single or few antioxidants to treat neuronal dysfunction may be termed as too simple to combat the complex ROS metabolism due to their results seen in clinical trials. An effective approach to antioxidant therapy would be to decrease ROS generation and upregulate the various intracellular and mitochondrial antioxidant defense system. For example, Nrf2 activates the antioxidant enzyme network and is termed as the master regulator of redox homeostasis. Therefore, therapeutic target of Nrf2 in the neuron offers a reliable means of regulating oxidative stress. Although, however, controlling oxidative stress alone may not be enough to target neurodegenerative diseases, the restoration of the neuronal function may depend also on targeting some other cell survival pathways. A considerable understanding of ROS biology will also provide insights into what can be targeted than what we have at present.

\section{Conclusion}

The underlying mechanisms of neurodegenerative disorders are not fully understood; however, there is strong evidence that redox imbalance not only plays a key role but mostly precedes neurodegenerative manifestations. Redox control in physiologic processes is important for maintaining the redox balance and for achieving redox homeostasis. Cells counteract redox imbalance by harnessing an array of both endogenous and exogenous redox-active substances through multiple cellular processes or pathways. Identifying and targeting these redox-regulated pathways in neurodegeneration may provide an avenue for newer treatment strategies. Moreover, as our understanding of the role of redox-regulated events in neurodegeneration becomes clearer, compounds such as phytochemicals that have antioxidative, anti-inflammatory, and anticholinesterase properties may be explored as a source of new treatments for neurodegenerative disorders in the future.

$\begin{array}{ll}\text { Abbreviations } \\ \text { ND: } & \text { Neurodegenerative disease } \\ \text { PD: } & \text { Parkinson's disease } \\ \text { AD: } & \text { Alzheimer's disease } \\ \text { EAD: } & \text { Early Alzheimer's disease } \\ \text { MCI: } & \text { Mild cognitive impairment } \\ \text { SNpc: } & \text { Substantia nigra pars compacta } \\ \text { BBB: } & \text { Blood-brain barrier } \\ \text { SN: } & \text { Substantia nigra } \\ \text { CC: } & \text { Cerebral cortex } \\ \text { mtDNA: } & \text { Mitochondrial DNA } \\ \text { nNOS: } & \text { Neuronal nitric oxide synthase } \\ \text { eNOS: } & \text { Endothelial nitric oxide synthase } \\ \text { iNOS: } & \text { Inducible nitric oxide synthase } \\ \text { NADPH: } & \text { Nicotinamide adenine dinucleotide phosphate } \\ \text { NOX: } & \text { NADPH oxidase } \\ \text { LOX: } & \text { Lipoxygenase } \\ \text { COX: } & \text { Cyclooxygenase } \\ \text { XO: } & \text { Xanthine oxidase } \\ \mathrm{H}_{2} \mathrm{O}_{2}: & \text { Hydrogen peroxide } \\ \mathrm{O}_{2}:- & \text { Superoxide anion } \\ \text { ETC: } & \text { Electron transport chain } \\ \text { OH: } & \text { Hydroxyl radical } \\ \text { GSH: } & \text { Glutathione } \\ \text { NMDA: } & \text { N-Methyl-D-aspartate } \\ \text { HNE: } & \text { Hydroxynonenal } \\ \text { AChE: } & \text { Acetylcholinesterase } \\ \text { CoQ10: } & \text { Coenzyme Q10. } \\ & \end{array}$

\section{Data Availability}

All data are included in the manuscript.

\section{Conflicts of Interest}

The authors declare that they have no conflicts of interest.

\section{References}

[1] P. Villoslada, R. Baeza-Yates, and J. C. Masdeu, "Reclassifying neurodegenerative diseases," Nature Biomedical Engineering, vol. 4, no. 8, pp. 759-760, 2020.

[2] S. Karanth, P. T. Nelson, Y. Katsumata et al., "Prevalence and clinical phenotype of quadruple misfolded proteins in older adults," JAMA Neurology, vol. 77, no. 10, pp. 1299-1307, 2020. 
[3] C. Peng, J. Q. Trojanowski, and V. M. Y. Lee, "Protein transmission in neurodegenerative disease," Nature Reviews. Neurology, vol. 16, no. 4, pp. 199-212, 2020.

[4] R. V. Badhe, D. R. Chejara, P. Kumar, Y. E. Choonara, and V. Pillay, "Neurodegenerative disease conditions and genomic treatment for better health," in Genomics-Driven Healthcare, Y. Pathak, Ed., Adis, Singapore, 2018.

[5] A. Singh, R. Kukreti, L. Saso, and S. Kukreti, "Oxidative stress: a key modulator in neurodegenerative diseases," Molecules, vol. 24, no. 8, p. 1583, 2019.

[6] C. Cid-Castro, D. R. Hernandez-Espinosa, and J. Moran, "ROS as regulators of mitochondrial dynamics in neurons," Cellular and Molecular Neurobiology, vol. 38, no. 5, pp. 995-1007, 2018.

[7] H. Yaribeygi, Y. Panahi, B. Javadi, and A. Sahebkar, "The underlying role of oxidative stress in neurodegeneration: a mechanistic review," CNS \& Neurological Disorders Drug Targets, vol. 17, no. 3, pp. 207-215, 2018.

[8] A. Haque, R. Polcyn, D. Matzelle, and N. L. Banik, "New insights into the role of neuron-specific enolase in neuroinflammation, neurodegeneration, and neuroprotection," Brain Sciences, vol. 8, no. 2, p. 33, 2018.

[9] A. Sarrafchi, M. Bahmani, H. Shirzad, and M. RafieianKopaei, “Oxidative stress and Parkinson's disease: new hopes in treatment with herbal antioxidants," Current Pharmaceutical Design, vol. 22, no. 2, pp. 238-246, 2016.

[10] M. Redza-Dutordoir and D. A. Averill-Bates, "Activation of apoptosis signalling pathways by reactive oxygen species," Biochimica et Biophysica Acta, vol. 1863, no. 12, pp. 29772992, 2016.

[11] P. R. Angelova and A. Y. Abramov, "Functional role of mitochondrial reactive oxygen species in physiology," Free Radical Biology \& Medicine, vol. 100, pp. 81-85, 2016.

[12] A. V. Snezhkina, A. V. Kudryavtseva, O. L. Kardymon et al., "ROS generation and antioxidant defense systems in normal and malignant cells," Oxidative Medicine and Cellular Longevity, vol. 2019, Article ID 6175804, 17 pages, 2019.

[13] F. Collin, "Chemical basis of reactive oxygen species reactivity and involvement in neurodegenerative diseases," International Journal of Molecular Sciences, vol. 20, no. 10, p. 2407, 2019.

[14] M. Valko, K. Jomova, C. J. Rhodes, K. Kuca, and K. Musilek, "Redox- and non-redox-metal-induced formation of free radicals and their role in human disease," Archives of Toxicology, vol. 90, no. 1, pp. 1-37, 2016.

[15] N. Asiimwe, S. G. Yeo, M. S. Kim, J. Jung, and N. Y. Jeong, "Nitric oxide: exploring the contextual link with Alzheimer's disease," Oxidative Medicine and Cellular Longevity, vol. 2016, Article ID 7205747, 10 pages, 2016.

[16] T. Nakamura and S. A. Lipton, "Aberrant nitric oxide signaling contributes to protein misfolding in neurodegenerative diseases via S-nitrosylation and tyrosine nitration," Nitric Oxide, L. J. Ignarro and B. A. Freeman, Eds., pp. 373-384, 2017.

[17] M. Ramalingam and S. J. Kim, "Reactive oxygen/nitrogen species and their functional correlations in neurodegenerative diseases," Journal of Neural Transmission (Vienna), vol. 119, no. 8, pp. 891-910, 2012.

[18] M. Virarkar, L. Alappat, P. G. Bradford, and A. B. Awad, "Larginine and nitric oxide in CNS function and neurodegener- ative diseases," Critical Reviews in Food Science and Nutrition, vol. 53, no. 11, pp. 1157-1167, 2013.

[19] U. Forstermann and W. C. Sessa, "Nitric oxide synthases: regulation and function," European Heart Journal, vol. 33, no. 7, pp. 829-837, 2012.

[20] O. Ifeanyi, "A review on free radicals and antioxidants," International Journal of Research in Medical Sciences, vol. 4, no. 2, pp. 123-133, 2018.

[21] C. Guo, L. Sun, X. Chen, and D. Zhang, "Oxidative stress, mitochondrial damage and neurodegenerative diseases," Neural Regeneration Research, vol. 8, no. 21, pp. 2003-2014, 2013.

[22] T. Cali, D. Ottolini, and M. Brini, "Mitochondria, calcium, and endoplasmic reticulum stress in Parkinson's disease," BioFactors, vol. 37, no. 3, pp. 228-240, 2011.

[23] G. H. Kim, J. E. Kim, S. J. Rhie, and S. Yoon, "The role of oxidative stress in neurodegenerative diseases," Exp Neurobiol, vol. 24, no. 4, pp. 325-340, 2015.

[24] N. Nissanka and C. T. Moraes, "Mitochondrial DNA damage and reactive oxygen species in neurodegenerative disease," FEBS Letters, vol. 592, no. 5, pp. 728-742, 2018.

[25] M. al Shahrani, S. Heales, I. Hargreaves, and M. Orford, "Oxidative Stress: Mechanistic Insights into Inherited Mitochondrial Disorders and Parkinson's Disease," Journal of Clinical Medicine, vol. 6, no. 11, p. 100, 2017.

[26] I. Badillo-Ramirez, J. M. Saniger, and S. Rivas-Arancibia, "5S-Cysteinyl-dopamine, a neurotoxic endogenous metabolite of dopamine: implications for Parkinson's disease," Neurochemistry International, vol. 129, p. 104514, 2019.

[27] P. Pradhan, O. Majhi, A. Biswas, V. K. Joshi, and D. Sinha, "Enhanced accumulation of reduced glutathione by scopoletin improves survivability of dopaminergic neurons in Parkinson's model," Cell Death \& Disease, vol. 11, no. 9, p. 739, 2020.

[28] L. Mezzaroba, D. F. Alfieri, A. N. Colado Simao, and E. M. Vissoci Reiche, "The role of zinc, copper, manganese and iron in neurodegenerative diseases," Neurotoxicology, vol. 74, pp. 230-241, 2019.

[29] S. Hu, H. Hu, S. Mak et al., "A novel tetramethylpyrazine derivative prophylactically protects against glutamateinduced excitotoxicity in primary neurons through the blockage of N-methyl-D-aspartate receptor," Frontiers in Pharmacology, vol. 9, p. 73, 2018.

[30] A. Martin-Bastida, B. S. Tilley, S. Bansal, S. M. Gentleman, D. T. Dexter, and R. J. Ward, "Iron and inflammation: in vivo and post-mortem studies in Parkinson's disease," Journal of Neural Transmission (Vienna), vol. 128, no. 1, pp. 15-25, 2021.

[31] G. A. Salvador, "Iron in neuronal function and dysfunction," BioFactors, vol. 36, no. 2, pp. 103-110, 2010.

[32] T. Moos and E. H. Morgan, "The significance of the mutated divalent metal transporter (DMT1) on iron transport into the Belgrade rat brain," Journal of Neurochemistry, vol. 88, no. 1, pp. 233-245, 2004.

[33] T. Moos and E. H. Morgan, "The metabolism of neuronal iron and its pathogenic role in neurological disease: review," Annals of the New York Academy of Sciences, vol. 1012, no. 1, pp. 14-26, 2004.

[34] M. I. Flydal, T. A. Kråkenes, M. D. S. Tai, M. P. A. Tran, K. Teigen, and A. Martinez, "Levalbuterol lowers the feedback inhibition by dopamine and delays misfolding and 
aggregation in tyrosine hydroxylase," Biochimie, vol. 183, pp. 126-132, 2020.

[35] B. Lozoff and M. K. Georgieff, "Iron deficiency and brain development," Seminars in Pediatric Neurology, vol. 13, no. 3, pp. 158-165, 2006.

[36] Y. E. Yoo, J. H. Hong, K. C. Hur, E. S. Oh, and J. M. Chung, "Iron enhances NGF-induced neurite outgrowth in PC12 cells," Molecules and Cells, vol. 17, no. 2, pp. 340-346, 2004.

[37] H. Jiang, N. Song, Q. Jiao, L. Shi, and X. Du, "Iron pathophysiology in Parkinson diseases," Advances in Experimental Medicine and Biology, vol. 1173, pp. 45-66, 2019.

[38] A. Gegotek and E. Skrzydlewska, "Biological effect of protein modifications by lipid peroxidation products," Chemistry and Physics of Lipids, vol. 221, pp. 46-52, 2019.

[39] G. Barrera, S. Pizzimenti, M. Daga et al., "Lipid peroxidationderived aldehydes, 4-hydroxynonenal and malondialdehyde in aging-related disorders," Antioxidants (Basel), vol. 7, no. 8, p. 102, 2018.

[40] M. M. Gaschler and B. R. Stockwell, "Lipid peroxidation in cell death," Biochemical and Biophysical Research Communications, vol. 482, no. 3, pp. 419-425, 2017.

[41] O. V. Taso, A. Philippou, A. Moustogiannis, E. Zevolis, and M. Koutsilieris, "Lipid peroxidation products and their role in neurodegenerative diseases," Annals of Research Hospitals, vol. 3, p. 2, 2019.

[42] H. Y. Liu, J. R. Gale, I. J. Reynolds, J. H. Weiss, and E. Aizenman, "The Multifaceted Roles of Zinc in Neuronal Mitochondrial Dysfunction," Biomedicine, vol. 9, no. 5, p. $489,2021$.

[43] K. M. Noh and J. Y. Koh, "Induction and activation by zinc of NADPH oxidase in cultured cortical neurons and astrocytes," The Journal of Neuroscience, vol. 20, no. 23, p. RC111, 2000.

[44] K. E. Dineley, T. V. Votyakova, and I. J. Reynolds, “Zinc inhibition of cellular energy production: implications for mitochondria and neurodegeneration," Journal of Neurochemistry, vol. 85, no. 3, pp. 563-570, 2003.

[45] D. Malinska, B. Kulawiak, A. P. Kudin et al., "Complex IIIdependent superoxide production of brain mitochondria contributes to seizure-related ROS formation," Biochimica et Biophysica Acta, vol. 1797, no. 6-7, pp. 1163-1170, 2010.

[46] K. Bedard and K. H. Krause, "The NOX family of ROSgenerating NADPH oxidases: physiology and pathophysiology," Physiological Reviews, vol. 87, no. 1, pp. 245-313, 2007.

[47] G. Salazar, J. Huang, R. G. Feresin, Y. Zhao, and K. K. Griendling, "Zinc regulates Nox1 expression through a NF- $\kappa \mathrm{B}$ and mitochondrial ROS dependent mechanism to induce senescence of vascular smooth muscle cells," Free Radical Biology \& Medicine, vol. 108, pp. 225-235, 2017.

[48] V. P. Bharathi, M. Govindaraju, A. P. Palanisamy, K. Sambamurti, and K. S. Rao, "Molecular toxicity of aluminium in relation to neurodegeneration," The Indian Journal of Medical Research, vol. 128, no. 4, pp. 545-556, 2008.

[49] C. Exley, "The aluminium-amyloid cascade hypothesis and Alzheimer's disease," Sub-Cellular Biochemistry, vol. 38, pp. 225-234, 2005.

[50] R. J. Castellani, P. I. Moreira, G. Liu et al., "Iron: the redoxactive center of oxidative stress in Alzheimer disease," Neurochemical Research, vol. 32, no. 10, pp. 1640-1645, 2007.

[51] C. A. Rottkamp, A. Nunomura, A. K. Raina, L. M. Sayre, G. Perry, and M. A. Smith, "Oxidative stress, antioxidants, and Alzheimer disease," Alzheimer Disease and Associated Disorders, vol. 14, Supplement, pp. S62-S66, 2000.

[52] O. B. Tysnes and A. Storstein, "Epidemiology of Parkinson's disease," Journal of Neural Transmission (Vienna), vol. 124, no. 8, pp. 901-905, 2017.

[53] Z. Li, Z. Zheng, J. Ruan, Z. Li, and C. M. Tzeng, "Chronic inflammation links cancer and Parkinson's disease," Frontiers in Aging Neuroscience, vol. 8, p. 126, 2016.

[54] C. Marras, C. G. Canning, and S. M. Goldman, "Environment, lifestyle, and Parkinson's disease: implications for prevention in the next decade," Movement Disorders, vol. 34, no. 6, pp. 801-811, 2019.

[55] M. T. Hayes, "Parkinson's disease and parkinsonism," The American Journal of Medicine, vol. 132, no. 7, pp. 802-807, 2019.

[56] S. Manoharan, G. J. Guillemin, R. S. Abiramasundari, M. M. Essa, M. Akbar, and M. D. Akbar, "The role of reactive oxygen species in the pathogenesis of Alzheimer's disease, Parkinson's disease, and Huntington's disease: a mini review," Oxidative Medicine and Cellular Longevity, vol. 2016, Article ID 8590578, 15 pages, 2016.

[57] S. Y. Pang, P. W. L. Ho, H. F. Liu et al., "The interplay of aging, genetics and environmental factors in the pathogenesis of Parkinson's disease," Translational Neurodegeneration, vol. 8, no. 1, p. 23, 2019.

[58] E. S. Chocron, E. Munkacsy, and A. M. Pickering, "Cause or casualty: the role of mitochondrial DNA in aging and ageassociated disease," Biochimica et Biophysica Acta-Molecular Basis of Disease, vol. 1865, no. 2, pp. 285-297, 2019.

[59] M. R. Silver, B. A. Racette, U. Dube, I. M. Faust, and S. Searles Nielsen, "Well water and Parkinson's disease in Medicare beneficiaries: a nationwide case-control study," Journal of Parkinson's Disease, vol. 10, no. 2, pp. 693-705, 2020.

[60] B. Doktór, M. Damulewicz, and E. Pyza, "Overexpression of mitochondrial ligases reverses rotenone-induced effects in a Drosophila model of Parkinson's disease," Frontiers in Neuroscience, vol. 13, p. 94, 2019.

[61] V. Lawana and J. R. Cannon, "Rotenone neurotoxicity: relevance to Parkinson's disease," in Advances in Neurotoxicolog, M. Aschner and L. G. Costa, Eds., pp. 209-254, Academic Press, 2020.

[62] C. Vaccari, R. El Dib, and J. L. V. de Camargo, "Paraquat and Parkinson's disease: a systematic review protocol according to the OHAT approach for hazard identification," Systematic Reviews, vol. 6, no. 1, p. 98, 2017.

[63] B. G. Trist, D. J. Hare, and K. L. Double, "Oxidative stress in the aging substantia nigra and the etiology of Parkinson's disease," Aging Cell, vol. 18, no. 6, article e13031, 2019.

[64] E. Monzani, S. Nicolis, S. Dell'Acqua et al., "Dopamine, oxidative stress and protein-quinone modifications in Parkinson's and other neurodegenerative diseases," Angewandte Chemie (International Ed. in English), vol. 58, no. 20, pp. 6512-6527, 2019.

[65] A. R. Carta, G. Mulas, M. Bortolanza et al., "l-DOPA-induced dyskinesia and neuroinflammation: do microglia and astrocytes play a role?," The European Journal of Neuroscience, vol. 45, no. 1, pp. 73-91, 2017.

[66] R. A. Maki, M. Holzer, K. Motamedchaboki et al., "Human myeloperoxidase (hMPO) is expressed in neurons in the substantia nigra in Parkinson's disease and in the hMPO- $\alpha$ synuclein-A53T mouse model, correlating with increased 
nitration and aggregation of $\alpha$-synuclein and exacerbation of motor impairment," Free Radical Biology \& Medicine, vol. 141, pp. 115-140, 2019.

[67] O. Karlsson and N. G. Lindquist, "Melanin and neuromelanin binding of drugs and chemicals: toxicological implications," Archives of Toxicology, vol. 90, no. 8, pp. 1883-1891, 2016.

[68] L. D. Coles, P. J. Tuite, G. Öz et al., "Repeated-dose oral Nacetylcysteine in Parkinson's disease: pharmacokinetics and effect on brain glutathione and oxidative stress," Journal of Clinical Pharmacology, vol. 58, no. 2, pp. 158-167, 2018.

[69] R. Kaur, S. Mehan, and S. Singh, "Understanding multifactorial architecture of Parkinson's disease: pathophysiology to management," Neurological Sciences, vol. 40, no. 1, pp. 1323, 2019.

[70] X. Jiang, T. Jin, H. Zhang et al., "Current progress of mitochondrial quality control pathways underlying the pathogenesis of Parkinson's disease," Oxidative Medicine and Cellular Longevity, vol. 2019, Article ID 4578462, 11 pages, 2019.

[71] S. R. Subramaniam and M. F. Chesselet, "Mitochondrial dysfunction and oxidative stress in Parkinson's disease," Progress in Neurobiology, vol. 106-107, pp. 17-32, 2013.

[72] A. Tramutola, C. Lanzillotta, M. Perluigi, and D. A. Butterfield, "Oxidative stress, protein modification and Alzheimer disease," Brain Research Bulletin, vol. 133, pp. 88-96, 2017.

[73] Alzehimer's association, "2020 Alzheimer's disease facts and figures," Alzheimers Dement, vol. 16, no. 3, pp. 391-460, 2020.

[74] L. Mucke, “Alzheimer's disease,” Nature, vol. 461, no. 7266, pp. 895-897, 2009.

[75] Y. W. Wan, R. al-Ouran, C. G. Mangleburg et al., "MetaAnalysis of the Alzheimer's Disease Human Brain Transcriptome and Functional Dissection in Mouse Models," Cell Reports, vol. 32, no. 2, p. 107908, 2020.

[76] R. J. Bateman, N. R. Barthelemy, and K. Horie, "Another step forward in blood-based diagnostics for Alzheimer's disease," Nature Medicine, vol. 26, no. 3, pp. 314-316, 2020.

[77] A. F. Shah, J. A. Morris, and M. Wray, "Pathogenesis of Alzheimer's disease: multiple interacting causes against which amyloid precursor protein protects," Medical Hypotheses, vol. 143, p. 110035, 2020.

[78] R. J. O'Brien and P. C. Wong, "Amyloid precursor protein processing and Alzheimer's disease," Annual Review of Neuroscience, vol. 34, no. 1, pp. 185-204, 2011.

[79] S. Hunter and C. Brayne, "Understanding the roles of mutations in the amyloid precursor protein in Alzheimer disease," Molecular Psychiatry, vol. 23, no. 1, pp. 81-93, 2018.

[80] A. Tsatsanis, B. X. Wong, A. P. Gunn et al., "Amyloidogenic processing of Alzheimer's disease $\beta$-amyloid precursor protein induces cellular iron retention," Molecular Psychiatry, vol. 25, no. 9, pp. 1958-1966, 2020.

[81] W. H. Habig, M. J. Pabst, and W. B. Jakoby, "Glutathione Stransferases: the first enzymatic step in mercapturic acid formation," The Journal of Biological Chemistry, vol. 249, no. 22, pp. 7130-7139, 1974.

[82] X. Wang, B. Su, L. Zheng, G. Perry, M. A. Smith, and X. Zhu, "The role of abnormal mitochondrial dynamics in the pathogenesis of Alzheimer's disease," Journal of Neurochemistry, vol. 109, Supplement 1, pp. 153-159, 2009.

[83] M. H. Yan, X. Wang, and X. Zhu, "Mitochondrial defects and oxidative stress in Alzheimer disease and Parkinson disease," Free Radical Biology \& Medicine, vol. 62, pp. 90-101, 2013.
[84] M. Blurton-Jones and F. LaFerla, "Pathways by which Abeta facilitates tau pathology," Current Alzheimer Research, vol. 3, no. 5, pp. 437-448, 2006.

[85] S. Oddo, A. Caccamo, J. D. Shepherd et al., “Triple-transgenic model of Alzheimer's disease with plaques and tangles: intracellular A $\beta$ and synaptic dysfunction," Neuron, vol. 39, no. 3, pp. 409-421, 2003.

[86] S. Muralidar, S. V. Ambi, S. Sekaran, D. Thirumalai, and B. Palaniappan, "Role of tau protein in Alzheimer's disease: the prime pathological player," International Journal of Biological Macromolecules, vol. 163, pp. 1599-1617, 2020.

[87] M. Amir Mishan, M. Rezaei Kanavi, K. Shahpasand, and H. Ahmadieh, "Pathogenic tau protein species: promising therapeutic targets for ocular neurodegenerative diseases," Journal of Ophthalmic and Vision Research, vol. 14, no. 4, pp. 491-505, 2019.

[88] A. D. Alonso, L. S. Cohen, C. Corbo et al., "Hyperphosphorylation of tau associates with changes in its function beyond microtubule stability," Frontiers in Cellular Neuroscience, vol. 12, p. 338, 2018.

[89] J. Neddens, M. Temmel, S. Flunkert et al., "Phosphorylation of different tau sites during progression of Alzheimer's disease," Acta Neuropathologica Communications, vol. 6, no. 1, p. 52, 2018.

[90] A. J. Moszczynski, M. Gohar, K. Volkening, C. Leystra-Lantz, W. Strong, and M. J. Strong, "Thr ${ }^{175}$-phosphorylated tau induces pathologic fibril formation via GSK3 $\beta$-mediated phosphorylation of $\mathrm{Thr}^{231}$ in vitro," Neurobiology of Aging, vol. 36, no. 3, pp. 1590-1599, 2015.

[91] H. Zhao, R. Chang, H. Che et al., "Hyperphosphorylation of tau protein by calpain regulation in retina of Alzheimer's disease transgenic mouse," Neuroscience Letters, vol. 551, pp. 12-16, 2013.

[92] D. A. Butterfield, M. L. Bader Lange, and R. Sultana, "Involvements of the lipid peroxidation product, HNE, in the pathogenesis and progression of Alzheimer's disease," Biochimica et Biophysica Acta, vol. 1801, no. 8, pp. 924-929, 2010.

[93] Y. Zhao and B. Zhao, "Oxidative stress and the pathogenesis of Alzheimer's disease," Oxidative Medicine and Cellular Longevity, vol. 2013, Article ID 316523, 10 pages, 2013.

[94] J. E. Selfridge, L. E, J. Lu, and R. H. Swerdlow, "Role of mitochondrial homeostasis and dynamics in Alzheimer's disease," Neurobiology of Disease, vol. 51, pp. 3-12, 2013.

[95] F. Cioffi, R. H. I. Adam, and K. Broersen, "Molecular mechanisms and genetics of oxidative stress in Alzheimer's disease," Journal of Alzheimer's Disease, vol. 72, no. 4, pp. 981-1017, 2019.

[96] C. K. Haluska, M. S. Baptista, A. U. Fernandes, A. P. Schroder, C. M. Marques, and R. Itri, "Photo-activated phase separation in giant vesicles made from different lipid mixtures," Biochimica et Biophysica Acta, vol. 1818, no. 3, pp. 666-672, 2012.

[97] C. D. Aluise, R. A. S. Robinson, T. L. Beckett et al., "Preclinical Alzheimer disease: brain oxidative stress, $\mathrm{A} \beta$ peptide and proteomics," Neurobiology of Disease, vol. 39, no. 2, pp. 221-228, 2010.

[98] C. D. Aluise, R. A. S. Robinson, J. Cai, W. M. Pierce, W. R. Markesbery, and D. A. Butterfield, "Redox proteomics analysis of brains from subjects with amnestic mild cognitive impairment compared to brains from subjects with 
preclinical Alzheimer's disease: insights into memory loss in MCI," Journal of Alzheimer's Disease, vol. 23, no. 2, pp. 257-269, 2011.

[99] E. Giraldo, A. Lloret, T. Fuchsberger, and J. Vina, “A $\beta$ and tau toxicities in Alzheimer's are linked _via_ oxidative stressinduced p38 activation: protective role of vitamin E," Redox Biology, vol. 2, pp. 873-877, 2014.

[100] N. Bulat and C. Widmann, "Caspase substrates and neurodegenerative diseases," Brain Research Bulletin, vol. 80, no. 4-5, pp. 251-267, 2009.

[101] X. Yang, P. Cai, Q. Liu et al., "Novel 8-hydroxyquinoline derivatives targeting _ $\beta_{-}$- amyloid aggregation, metal chelation and oxidative stress against Alzheimer's disease," Bioorganic \& Medicinal Chemistry, vol. 26, no. 12, pp. 3191-3201, 2018.

[102] K. P. Kepp, "Bioinorganic chemistry of Alzheimer's disease," Chemical Reviews, vol. 112, no. 10, pp. 5193-5239, 2012.

[103] P. Zatta, D. Drago, S. Bolognin, and S. L. Sensi, “Alzheimer's disease, metal ions and metal homeostatic therapy," Trends in Pharmacological Sciences, vol. 30, no. 7, pp. 346-355, 2009.

[104] S. Hernando, O. Gartziandia, E. Herran, J. L. Pedraz, M. Igartua, and R. M. Hernandez, "Advances in nanomedicine for the treatment of Alzheimer's and Parkinson's diseases," Nanomedicine (London, England), vol. 11, no. 10, pp. 1267-1285, 2016.

[105] F. Pohl and P. Kong Thoo Lin, "The potential use of plant natural products and plant extracts with antioxidant properties for the prevention/treatment of neurodegenerative diseases: in vitro, in vivo and clinical trials," Molecules, vol. 23, no. 12 , p. $3283,2018$.

[106] I. H. Cho, "Effects of Panax ginseng in neurodegenerative diseases," Journal of Ginseng Research, vol. 36, no. 4, pp. 342353, 2012.

[107] M. di Paolo, L. Papi, F. Gori, and E. Turillazzi, "Natural products in neurodegenerative diseases: a great promise but an ethical challenge," International Journal of Molecular Sciences, vol. 20, no. 20, p. 5170, 2019.

[108] N. S. Mohd Sairazi and K. N. S. Sirajudeen, "Natural products and their bioactive compounds: neuroprotective potentials against neurodegenerative diseases," Evidence-based Complementary and Alternative Medicine, vol. 2020, Article ID 6565396, 30 pages, 2020.

[109] A. Negida, A. Menshawy, G. el Ashal et al., "Coenzyme Q10 for patients with Parkinson's disease: a systematic review and meta-analysis," CNS \& Neurological Disorders Drug Targets, vol. 15, no. 1, pp. 45-53, 2016.

[110] H. W. Park, C. G. Park, M. Park et al., "Intrastriatal administration of coenzyme Q10 enhances neuroprotection in a Parkinson's disease rat model," Scientific Reports, vol. 10, no. 1, p. 9572, 2020.

[111] Z. G. Zhu, M. X. Sun, W. L. Zhang, W. W. Wang, Y. M. Jin, and C. L. Xie, "The efficacy and safety of coenzyme Q10 in Parkinson's disease: a meta-analysis of randomized controlled trials," Neurological Sciences, vol. 38, no. 2, pp. 215224, 2017.

[112] J. S. Park, R. L. Davis, and C. M. Sue, "Mitochondrial dysfunction in Parkinson's disease: new mechanistic insights and therapeutic perspectives," Current Neurology and Neuroscience Reports, vol. 18, no. 5, p. 21, 2018.

[113] D. Charvin, R. Medori, R. A. Hauser, and O. Rascol, "Therapeutic strategies for Parkinson disease: beyond dopaminergic drugs," Nature Reviews. Drug Discovery, vol. 17, no. 11, pp. 804-822, 2018.

[114] A. Bender and T. Klopstock, "Creatine for neuroprotection in neurodegenerative disease: end of story?" Amino Acids, vol. 48, no. 8, pp. 1929-1940, 2016.

[115] S. L. Hor, S. L. Teoh, and W. L. Lim, "Plant polyphenols as neuroprotective agents in Parkinson's disease targeting oxidative stress," Current Drug Targets, vol. 21, no. 5, pp. 458476, 2020.

[116] A. Singh, P. Tripathi, A. K. Yadawa, and S. Singh, "Promising polyphenols in Parkinson's disease therapeutics," Neurochemical Research, vol. 45, no. 8, pp. 1731-1745, 2020.

[117] T. Satoh, S. R. McKercher, and S. A. Lipton, "Nrf2/AREmediated antioxidant actions of pro-electrophilic drugs," Free Radical Biology \& Medicine, vol. 65, pp. 645-657, 2013.

[118] H. Lou, X. Jing, X. Wei, H. Shi, D. Ren, and X. Zhang, "Naringenin protects against 6-OHDA-induced neurotoxicity via activation of the Nrf2/ARE signaling pathway," Neuropharmacology, vol. 79, pp. 380-388, 2014.

[119] K. Gunjima, R. Tomiyama, K. Takakura et al., "3,4-Dihydroxybenzalacetone protects against Parkinson's diseaserelated neurotoxin 6-OHDA through Akt/Nrf2/glutathione pathway," Journal of Cellular Biochemistry, vol. 115, no. 1, pp. 151-160, 2014.

[120] L. Wei, L. Ding, M. S. Mo et al., "Wnt3a protects SH-SY5Y cells against 6-hydroxydopamine toxicity by restoration of mitochondria function," Translational Neurodegeneration, vol. 4, no. 1, p. 11, 2015.

[121] F. Morroni, A. Tarozzi, G. Sita et al., "Neuroprotective effect of sulforaphane in 6-hydroxydopamine-lesioned mouse model of Parkinson's disease," Neurotoxicology, vol. 36, pp. 63-71, 2013.

[122] T. Sengupta, J. Vinayagam, R. Singh, P. Jaisankar, and K. P. Mohanakumar, "Plant-derived natural products for Parkinson's disease therapy," Advances in Neurobiology, vol. 12, pp. 415-496, 2016.

[123] A. Cuadrado, P. Moreno-Murciano, and J. Pedraza-Chaverri, "The transcription factor Nrf2 as a new therapeutic target in Parkinson's disease," Expert Opinion on Therapeutic Targets, vol. 13, no. 3, pp. 319-329, 2009.

[124] H. Kumar, H. W. Lim, S. V. More et al., "The role of free radicals in the aging brain and Parkinson's disease: convergence and parallelism," International Journal of Molecular Sciences, vol. 13, no. 8, pp. 10478-10504, 2012.

[125] A. Silva-Palacios, M. Ostolga-Chavarria, C. Zazueta, and M. Konigsberg, "Nrf2: molecular and epigenetic regulation during aging," Ageing Research Reviews, vol. 47, pp. 31-40, 2018.

[126] H. Jin, A. Kanthasamy, A. Ghosh, V. Anantharam, B. Kalyanaraman, and A. G. Kanthasamy, "Mitochondriatargeted antioxidants for treatment of Parkinson's disease: preclinical and clinical outcomes," Biochimica et Biophysica Acta, vol. 1842, no. 8, pp. 1282-1294, 2014.

[127] A. Camilleri and N. Vassallo, "The centrality of mitochondria in the pathogenesis and treatment of Parkinson's disease," CNS Neuroscience \& Therapeutics, vol. 20, no. 7, pp. 591602, 2014.

[128] K. H. Chang and C. M. Chen, "The role of oxidative stress in Parkinson's disease," Antioxidants (Basel), vol. 9, no. 7, p. 597, 2020.

[129] A. P. Duarte-Jurado, Y. Gopar-Cuevas, O. Saucedo-Cardenas et al., "Antioxidant Therapeutics in Parkinson's Disease: 
Current Challenges and Opportunities," Antioxidants (Basel), vol. 10, no. 3, p. 453, 2021.

[130] T. Jiang, Q. Sun, and S. Chen, “Oxidative stress: a major pathogenesis and potential therapeutic target of antioxidative agents in Parkinson's disease and Alzheimer's disease," Progress in Neurobiology, vol. 147, pp. 1-19, 2016.

[131] V. Conte, K. Uryu, S. Fujimoto et al., "Vitamin E reduces amyloidosis and improves cognitive function in Tg2576 mice following repetitive concussive brain injury," Journal of Neurochemistry, vol. 90, no. 3, pp. 758-764, 2004.

[132] H. Nakashima, T. Ishihara, O. Yokota et al., "Effects of $\alpha$ tocopherol on an animal model of tauopathies," Free Radical Biology \& Medicine, vol. 37, no. 2, pp. 176-186, 2004.

[133] S. Sung, Y. Yao, K. Uryu et al., "Early vitamin E supplementation in young but not aged mice reduces $A \beta$ levels and amyloid deposition in a transgenic model of Alzheimer's disease," The FASEB Journal, vol. 18, no. 2, pp. 323-325, 2004.

[134] R. J. Kryscio, E. L. Abner, A. Caban-Holt et al., “Association of antioxidant supplement use and dementia in the prevention of Alzheimer's disease by vitamin $\mathrm{E}$ and selenium trial (PREADViSE)," JAMA Neurology, vol. 74, no. 5, pp. 567573, 2017.

[135] P. Yang, D. Sheng, Q. Guo et al., "Neuronal mitochondriatargeted micelles relieving oxidative stress for delayed progression of Alzheimer's disease," Biomaterials, vol. 238, p. 119844, 2020.

[136] C. Gao, Y. Wang, J. Sun et al., "Neuronal mitochondriatargeted delivery of curcumin by biomimetic engineered nanosystems in Alzheimer's disease mice," Acta Biomaterialia, vol. 108, pp. 285-299, 2020.

[137] P. Srivastava, P. N. Tripathi, P. Sharma, and S. K. Shrivastava, "Design, synthesis, and evaluation of novel_N_-(4-phenoxybenzyl)aniline derivatives targeting acetylcholinesterase, $\beta$ amyloid aggregation and oxidative stress to treat Alzheimer's disease," Bioorganic \& Medicinal Chemistry, vol. 27, no. 16, pp. 3650-3662, 2019.

[138] M. van Bulck, A. Sierra-Magro, J. Alarcon-Gil, A. Perez-Castillo, and J. Morales-Garcia, "Novel Approaches for the Treatment of Alzheimer's and Parkinson's Disease," International Journal of Molecular Sciences, vol. 20, no. 3, p. 719, 2019.

[139] H. Q. Chen, Z. Y. Jin, X. J. Wang, X. M. Xu, L. Deng, and J. W. Zhao, "Luteolin protects dopaminergic neurons from inflammation-induced injury through inhibition of microglial activation," Neuroscience Letters, vol. 448, no. 2, pp. 175-179, 2008.

[140] S. S. Karuppagounder, S. K. Madathil, M. Pandey, R. Haobam, U. Rajamma, and K. P. Mohanakumar, "Quercetin up-regulates mitochondrial complex-I activity to protect against programmed cell death in rotenone model of Parkinson's disease in rats," Neuroscience, vol. 236, pp. 136-148, 2013. 